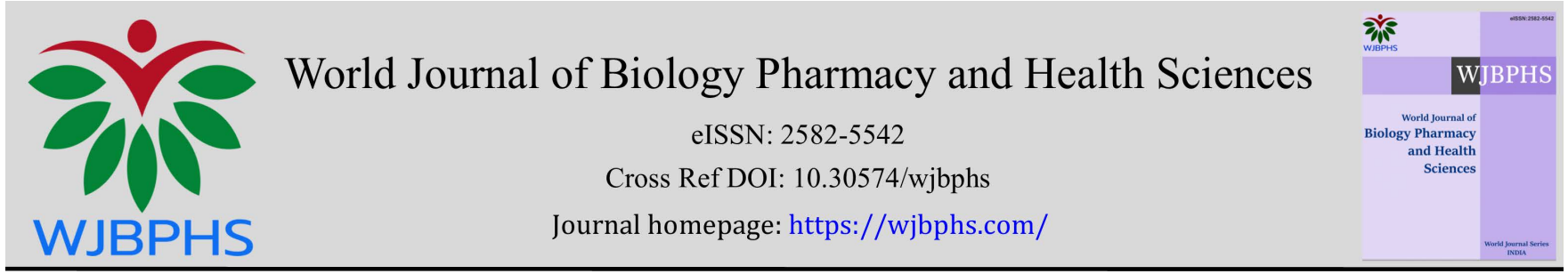

(REVIEW ARTICLE)

\title{
Role of diet in asthma and chronic obstructive pulmonary disease
}

\author{
Shaista Sumayya, Siddiqua Parveen, Mohammed Ashfaq Hussain and S P Srinivas Nayak* \\ Department of Pharmacy Practice, Sultan-ul-Uloom college of Pharmacy, JNTUH, Telangana, India.
}

World Journal of Biology Pharmacy and Health Sciences, 2021, 05(03), 053-063

Publication history: Received on 06 February 2021; revised on 08 March 2021; accepted on 10 March 2021

Article DOI: https://doi.org/10.30574/wjbphs.2021.5.3.0026

\begin{abstract}
Asthma is a chronic respiratory condition characterized by airway inflammation and hyper-reactivity. Asthma prevalence has continued to rise in recent decades as Western dietary patterns have become more pervasive. Evidence suggests that diets emphasizing the consumption of plant-based foods might protect against asthma development and improve asthma symptoms through their effects on systemic inflammation, oxidation, and microbial composition. However, some dietary patterns, such as the Western diet, which includes a high intake of refined grains, processed and red meats, and desserts, have pro-inflammatory effects. On the contrary, the Mediterranean diet, with high intake of fruits and vegetables has anti-inflammatory properties. Greater intake of dietary fibre has been consistently associated with reduced COPD risk, better lung function and reduced respiratory symptoms. The influence of food on asthma outcomes is of growing interest, but dietary habits of asthma patients are not commonly investigated in clinical practice. In this review, we focus on the impact of diet on asthma risk and asthma control. We also detail the influence of diet on obese patients with asthma.
\end{abstract}

Keywords: Asthma; COPD; Diet; Respiratory Health; Nutrition

\section{Introduction}

Asthma prevalence has been steadily rising since the 1980s. According to national surveillance data from the Centers for Disease Control, an estimated 6.8 million people had asthma in 1980 [1]. This number increased to 25.7 million persons diagnosed in 2010 [1]. In children, asthma prevalence was reported to be $3.5 \%$ in 1980 [1]. Thirty years later, that figure had jumped to $9.5 \%$ of children aged $0-17$ years $[1,2]$. The disease can be fatal. In 2009 , the rate of deaths with asthma as the underlying cause per 10,000 persons with asthma was 1.9 in adults and 0.3 in children [1]. The asthma death rate was highest among individuals aged 65 years and older [2]. The disease is more common in African Americans (11.9\% in 2010) than in white Americans (7.8\%) [1,2]. According to the 2012 National Vital Statistics System and National Health Interview Survey, asthma mortality was also higher in African Americans (24.9\%) than white persons (8.4\%) in 2010 [1]. Persons with a family income below the federal poverty threshold also had higher asthma prevalence [1, 3]. In 2010, asthma prevalence was 2.5\% higher among individuals with a family income under the federal poverty threshold than individuals with a family income at or above the poverty threshold [1]. Holsey et al suggest that disparities in asthma prevalence and mortality can be attributed to lower socioeconomic status and the greater health needs of minority groups. Minority groups are more likely to be uninsured or have non-private insurance, and subsequently less likely to receive quality medical care and afford prescription medication. In addition, minority and low-income patients are more likely to report difficulty obtaining appointments and less likely to be seen by an asthma specialist. Socioeconomically disadvantaged individuals are also more likely to consume high-fat foods and fewer fruits and vegetables than individuals with a higher socioeconomic status. These disparities in healthcare and diet quality might explain the increased asthma prevalence in low-income families [5]. The direct influence of food on asthma outcomes regardless of allergic status has emerged more recently [6], with dietary factors showing the potential

\section{${ }^{*}$ Corresponding author: Dr. S P Srinivas Nayak}

Assistant Professor, Dept. Of Pharmacy Practice, Sultan-ul-Uloom college of Pharmacy, JNTUH, Telangana, India..

Copyright (C) 2021 Author(s) retain the copyright of this article. This article is published under the terms of the Creative Commons Attribution Liscense 4.0. 
to be directly involved in asthma pathogenesis [6, 7]. Obese asthmatics have a distinct phenotype with a unique pathophysiology (low eosinophilic inflammation, low allergen sensitization) [8,9]. The specific role of diet on asthma outcomes in obese patients is also of growing interest due to their limited responsiveness to inhaled corticosteroids, as well as other difficulties faced when managing these patients $[10,11]$. The key question for clinicians is to know whether changes in the diet could benefit patients with asthma in routine practice. In this review, we will describe the impact of diet on asthma, and identify messages that can be used in asthma management. Given that obese asthmatic patients represent a particular group in terms of inflammation and clinical management, we will also focus on the effect of diet on asthma patients with obesity [11].

\section{Nutrition and respiratory health}

Next to smoking and physical activity, diet is an important and interrelated lifestyle factor not only for disease prevention but also contributing to heterogeneity in disease progression and prognosis. In addition to smoking and physical inactivity, evidence is accumulating that dietary habits are not only involved in the development of metabolic and cardiovascular diseases but may also influence etiology and progression of chronic obstructive pulmonary disease (COPD) [12]. Diet and nutrition are increasingly becoming recognized as modifiable contributors to chronic disease development and progression. Considerable evidence has emerged indicating the importance of dietary intake in obstructive lung diseases such as asthma and COPD in both early life and disease development $[12,13]$.

\subsection{Fried foods and salt on asthma}

Any food when fried becomes extra greasy and will lead to extra effort during digestion. The breakdown of fats takes longer in the digestive system and a sensation of being bloating can occur in the abdomen. The feeling of being bloated causes discomfort to the patient. This makes it difficult to take full breaths as the diaphragm hurts due to the extra gas produced by the digestive juices. Fried foods are also associated with easy weight gain. This extra fat usually accumulates in the area around the middle of the torso, putting more pressure on the diaphragm and causing discomfort for the patient during breathing. Some such foods that should be avoided include French fries, onion rings, fried chicken, fried fish, high salt content, jalapeno poppers, and deep-fried pickles [12].

\subsection{Aerated drinks in asthma}

This refers to any kind of drink which may have been aerated with carbon dioxide. They usually include artificial preservatives, sweeteners and colors, none of which are good for the health of a person suffering from COPD. The pressure in the middle of the torso affects the ease with which the patient can breathe. Furthermore, the sugars, sugar substitutes and caffeine which may be part of these drinks have no nutritive value for the patient. It is best to drink pure water to stay hydrated and allow the body enough fluid to carry out all metabolic activities. Therefore, one should avoid drinking sodas, energy drinks, colas and other aerated drinks [12].

\subsection{Cruciferous vegetables}

Since cruciferous vegetables have been known to have many health benefits, people make a special effort to include them in their diet. Common cruciferous vegetables being consumed include cauliflower, broccoli, radishes, Brussels sprouts, bokchoy, cabbage, collard greens, kale and arugula. Unfortunately, the extra fibre causes them to give patients with COPD indigestion and bloating due to the extra gas generated in the system. The bloating causes a difficulty in breathing for the patient [12].

\section{Mediterranean diet}

Various dietary patterns have been linked to the risk of respiratory disease [14]. The Mediterranean diet has been found to have protective effects for allergic respiratory diseases in epidemiological studies [15]. This dietary pattern consists of a high intake of minimally processed plant foods, namely; fruit, vegetables, breads, cereals, beans, nuts and seeds, low to moderate intake of dairy foods, fish, poultry and wine and low intake of red meat. High intakes of olive oil result in a dietary composition that is low in saturated fat though still moderate in total fat. In children, several studies showed that adherence to the Mediterranean diet is inversely associated with atopy and has a protective effect on atopy, wheezing and asthma symptoms $[16,17,18]$. The Mediterranean diet may also be important for maternal diet, as a study in Spain found that a high Mediterranean diet score during pregnancy was protective for persistent wheeze and atopic wheeze in children at 6.5 years of age [19]. 


\section{Western diet}

The "western" dietary pattern, prevalent in developed countries, is characterized by high consumption of refined grains, cured and red meats, desserts and sweets, French fries, and high-fat dairy products [20]. This pattern of intake has been associated with increased risk of asthma in children [21,22]. In adults, a western diet has been shown to be positively associated with increased frequency of asthma exacerbation, but not related to asthma risk. In addition, an acute challenge with a high fat fast food meal has been shown to worsen airway inflammation [23, 24]. Cross-sectional studies have also found that the "western" diet is associated with an increased risk of COPD [13].

\section{Fruits and vegetables}

Fruit and vegetable intake has been investigated for potential benefits in association with respiratory conditions due to their nutrient profile consisting of antioxidants, vitamins, minerals, fibre and phytochemicals. Epidemiological evidence reviewed by Saadeh et al. showed that fruit intake was associated with a low prevalence of wheezing and that cooked green vegetable intake was associated with a low prevalence of wheezing and asthma [25]. In adults, Grieger et al. discusses the heterogeneous nature of the data describing fruit and vegetable intake and lung function, with one study showing no effect on lung function of higher fruit and vegetable intake over 10 years, yet in another study, increased fruit intake over 2 years was associated with increased FEV1, while another study showed that a large decrease in fruit intake over 7 years was associated with decreased FEV1 [26, 27, 28]. Increased fruit and vegetable intake may be protective against COPD development, with consumption of a "prudent" diet including increased fruit and vegetables being protective against lung function decline [29]. Insufficient intake of fresh fruits and vegetables may result in deficiency of vitamins with antioxidant capacity. Conversely, long-term supplementation with vitamin E has been shown to reduce the risk of COPD [30].

\section{Omega-3 fatty acids and fish}

Omega-3 polyunsaturated fatty acids (PUFA) from marine sources and supplements have been shown to be antiinflammatory through several cellular mechanisms including their incorporation into cellular membranes and resulting altered synthesis of eicosanoids [31]. Experimental studies have shown that long chain omega-3 PUFA's decrease inflammatory cell production of pro-inflammatory prostaglandin (PG) E2, leukotriene (LT) B4 and activity of nuclear factor-kappaB $(\mathrm{NF}-\mathrm{KB})$, a potent inflammatory transcription factor [32, 33]. Long chain omega-3 PUFA's also down regulate pro-inflammatory cell cytokine production (interleukin-1 $\beta$ (IL-1 $\beta$ ), tumor necrosis factor- $\alpha$ (TNF- $\alpha$ )) by monocytes and macrophages, decrease expression of cellular adhesion molecules on monocytes and endothelial cells and reduce production of ROS in neutrophils [34]. Maternal dietary intake of oily fish was found to be protective of asthma in children 5 years of age if born to mothers with asthma and a recent systematic review of omega-3 fatty acid supplementation studies in women during pregnancy found that the risk of asthma development in children was reduced [35, 36]. Omega-3 PUFA may have positive effects in COPD, as higher levels of DHA in serum were found to decrease the risk of developing COPD [37]. Experimental studies in humans with COPD including supplementation with omega-3 found lower levels of TNF- $\alpha$ and improved rehabilitation outcomes[38], though no improvements were seen in FEV1 [39].

\section{Antioxidants and oxidative stress}

Dietary antioxidants are an important dietary factor in protecting against the damaging effects of oxidative stress in the airways, a characteristic of respiratory diseases [40]. Oxidative stress caused by reactive oxygen species (ROS), is generated in the lungs due to various exposures, such as air pollution, airborne irritants and typical airway inflammatory cell responses [41]. Also, increased levels of ROS generate further inflammation in the airways via activation of NF- $\kappa \mathrm{B}$ and gene expression of pro-inflammatory mediators [42]. Antioxidants including vitamin $\mathrm{C}$, vitamin E, flavonoids and carotenoids are abundantly present in fruits and vegetables, as well as nuts, vegetable oils, cocoa, red wine and green tea. $\alpha$-tocopherol is a form of vitamin $E$, which helps maintain integrity of membrane fatty acids, by inhibiting lipid peroxidation. Carotenoids are plant pigments and include; $\alpha$ - and $\beta$-carotene, lycopene, lutein and $\beta$ cryptoxanthin. This group of fat soluble antioxidants have been shown to benefit respiratory health due to their ability to scavenge ROS and reduce oxidative stress [26].

The antioxidant lycopene, present predominantly in tomatoes, may be beneficial in respiratory conditions, indeed lycopene intake has been positively correlated with FEV1 in both asthma and COPD and an intervention study in asthma showed that lycopene supplementation could suppress neutrophilic airway inflammation [43, 44]. Antioxidants may also be important in asthma during pregnancy, as while oxidative stress commonly increases during normal 
pregnancies, in women with asthma oxidative stress is heightened [45]. Improving antioxidant intake in pregnant women with asthma may be beneficial as poor fetal growth outcomes are associated with low levels of circulating antioxidants and dietary antioxidants are the first defense mechanism against ROS [26].

\section{Vitamin $C$ and vitamin $E$ in asthma}

Vitamin $\mathrm{C}$ has been enthusiastically investigated for benefits in asthma and links to asthma prevention. Vitamin $\mathrm{C}$ could inhibit NF- $\kappa$ B activation by IL-1, TNF- $\alpha$ and block production of IL-8. Observational studies in children showed consumption of fruit, a rich source of vitamin C, was related to reduced wheezing [46]. Despite the observational data linking vitamin $C$ to lung health, supplementation with vitamin $C$ has not been shown to reduce the risk of asthma [47]. Vitamin E works synergistically with vitamin C, as following neutralization of ROS, oxidized vitamin E isoforms can be processed back into their reduced form by vitamin C [48]. A study in humans showed that both $\alpha$ and $\gamma$-tocopherol may be effective in decreasing LPS induced neutrophilic inflammation [49]. In COPD, serum levels of vitamin E have been shown to be decreased during exacerbation, which suggests increased intake may be helpful to improve vitamin E concentrations [50]. Vitamin E has been shown to reduce biomarkers of oxidative stress in adults with COPD in one RCT [51]. In the Women's Health Study ( $\mathrm{n}=38,597)$, the risk of developing chronic lung disease over a 10 year supplementation period was reduced by $10 \%$ in women using vitamin E supplements (600 IU on alternate days) [52]. In COPD there is currently not enough evidence to make conclusions about vitamin E supplementation. As smoking and lung inflammation in COPD are known to cause significant oxidative stress, a reduction of the anti-oxidative capacity may have negative effects on the course of COPD.

\section{Role of vitamin $D$ in asthma}

Epidemiological studies show promising associations between vitamin D and lung health; however the mechanisms responsible for these effects are poorly understood. Vitamin D can be obtained from dietary sources or supplementation; however sun exposure is the main contributor to vitamin D levels [53]. While vitamin D has beneficial effects independent of UV exposure, it can be difficult to separate this potential confounder from direct effects of vitamin D on lung health $[54,55]$. Respiratory infections contribute to disease progression and exacerbation in both COPD and asthma. Vitamin D appears to have a protective role against the susceptibility to and severity of these infections as active vitamin $\mathrm{D}(1,25(\mathrm{OH}) 2 \mathrm{D})$ modifies production of antimicrobial cathelicidins and defensins that kill bacteria and induce wound repair [56,57]. Observational studies report that in children, low levels of vitamin D are associated with asthma exacerbation [58]. Blood vitamin D levels have also been correlated with lung function in COPD patients [60, 61]. COPD exacerbations are generally caused by viral or bacterial lung infections, and though vitamin D has a positive role in reducing infection, there is no evidence to support that vitamin $\mathrm{D}$ is associated with ameliorating exacerbations in COPD patients [62]. Vitamin D deficiency and insufficient intake of vitamins with antioxidant capacity (vitamins A, C and E) have been reported in COPD. Vitamin D has an important role in bone and calcium homeostasis but effects may occur beyond bone health, as anti-inflammatory, anti-infectious and anti-tumoural actions, as well as neuromuscular improvements, have been attributed to vitamin D [63]. For COPD, conflicting evidence exists on whether 25-OHD levels correlate with lung function decline, infectious exacerbations and muscular function [64 - 67]. In COPD, vitamin D deficiency frequently occurs because of smoke-induced skin ageing, reduced outdoor activity and low-quality dietary intake. Based on internationally accepted cut-offs, vitamin D deficiency (25-OHD levels, 20 ng.mL-1) is highly prevalent in COPD and increases with disease severity [68]. Daily intakes in addition to a minimal amount of ultraviolet radiation exposure vary with age but a dose of $800 \mathrm{IU}$ with $1 \mathrm{~g}$ calcium is considered to be largely sufficient. The potential of highdose supplementation to obtain other than calcaemic effects, including lung function decline and COPD exacerbations, needs further exploration [69].

\section{Role of minerals in asthma}

Some minerals have also been found to be protective in respiratory conditions. In children, increased intake of magnesium, calcium and potassium is inversely related to asthma prevalence [25]. Dietary magnesium may have beneficial bronchodilator effects in asthma [70]. Low dietary magnesium intake has been associated with negative effects on bronchial smooth muscle in severe asthma and with lower lung function in children [71, 72].However further evidence of positive therapeutic effects are required before its importance in asthma and recommendations can be determined [73]. Dietary intake of selenium has been shown to be lower in asthmatics compared to non-asthmatics and maternal plasma selenium levels were reported to be inversely associated with risk of asthma in children [74, 75]. Furthermore, results from a large well designed RCT in adults with asthma showed no positive benefit of selenium supplementation [76]. Studies on dietary intake of minerals and associations with COPD are sparse. Mineral intake may 
be important in respiratory diseases, yet evidence for supplementation is weak. It is likely that adequate intake of these nutrients in a whole diet approach is sufficient.

Table 1 Relationship of Nutrition and Obstructive Lung Diseases: Dietary factors that have been linked to respiratory disease. "YES" is Evidence suggesting positive effect, "NO" is evidence suggesting negative effect,"?" Evidence is lacking.

\begin{tabular}{|l|l|l|}
\hline \multirow{4}{*}{ Dietary patterns } & DIET & Asthma and COPD \\
\hline \multirow{4}{*}{ Weight status } & Mediterranean diet & YES \\
\cline { 2 - 3 } & Prudent diet & YES \\
\cline { 2 - 3 } & Western diet & NO \\
\cline { 2 - 3 } & Fast food & NO \\
\hline \multirow{4}{*}{ Antioxidants } & Healthy weight & YES \\
\cline { 2 - 3 } & Underweight & NO \\
\cline { 2 - 3 } & Overweight & NO \\
\hline \multirow{2}{*}{ Other nutrients } & Vitamin C & YES \\
\cline { 2 - 3 } & Vitamin E & YES \\
\cline { 2 - 3 } & Flavonoids & YES \\
\hline & Vitamin D & YES \\
\cline { 2 - 3 } & Minerals & $?$ \\
\hline
\end{tabular}

\section{Role of flavonoids in respiratory diseases}

Flavonoids are potent antioxidants and have anti-inflammatory as well as anti-allergic actions due in part, to their ability to neutralize ROS [77]. There are 6 classes of flavonoids including flavones, flavonols, flavanones, isoflavones and flavanols, which are widely distributed throughout the diet and found in fruit, vegetables, nuts, seeds, stems, flowers, roots, bark, dark chocolate, tea, wine and coffee [78]. In addition to reducing oxidative stress, in vitro experiments have found that many individual flavonoids have inhibitory effects on IgE mediated immune responses such as histamine secretion by mast cells, shift in cytokine production from Th- 2 to Th- 1 production and decreased NF- $\kappa \mathrm{B}$ activation and inhibition of TNF- $\alpha$ [79]. In humans, evidence from a case control study in adults showed that apple and red wine consumption, rich sources of flavonoids, was associated with reduced asthma prevalence and severity [47]. Three RCT's in adults with asthma using a product called pycnogenol, which contains a mixture of bioflavonoids, reported benefits including increased lung function, decreased symptoms and reduced need for rescue inhalers [80].

\section{Obesity, adipokines and respiratory disease}

In the obese state dietary intake of lipids leads to increased circulating free fatty acids which activate immune responses, such as activation of TLR4, leading to increased inflammation, both systemically and in the airways [13, 81]. Adipose tissue also secretes adipokines and asthmatic subjects have higher concentrations of circulating leptin than healthy controls [16] which are further increased in females, though leptin is associated with BMI in both males and females [82]. Leptin receptors are present in the bronchial and alveolar epithelial cells and leptin has been shown to induce activation of alveolar macrophages [83]. .Adiponectin, an anti-inflammatory adipokine, has beneficial effects in animal models of asthma [84]. COPD is characterised not only by pulmonary deficits but also by chronic systemic inflammation and co-morbidities which may develop in response to the metabolic dysregulation that occurs with excess adipose tissue [85]. Obesity, the resulting systemic inflammation and alterations in adipokines have significant negative effects in both asthma and COPD. While work examining the mechanisms of effect is extensive, evidence for interventions to improve the course of disease are limited to weight loss interventions in asthma at this stage.

\section{Undernutrition and respiratory disease}

Though underweight has not been well studied in asthma, an observational study in Japan reported that subjects with asthma who were underweight had poorer asthma control than their normal weight counterparts [86]. Amongst the 
obstructive lung diseases, undernutrition is most commonly recognized as a feature of COPD [87]. Weight loss, low body weight and muscle wasting are common in COPD patients with advanced disease and are associated with reduced survival time and an increased risk of exacerbation [88]. The causes of undernutrition in COPD are multifactorial and include reduced energy intake due to decreased appetite, depression, lower physical activity and dyspnea while eating [89]. In addition, resting energy expenditure is increased in COPD, likely due to higher energy demands from increased work of breathing [90]. Also, systemic inflammation which is a hallmark of COPD, may influence energy intake and expenditure [91]. Nutritional supplementation therapy in undernourished COPD patients has been shown to induce weight gain, increase fat free mass, increase grip strength and exercise tolerance as well as improve quality of life [92]. Other dietary nutrients have been investigated for the benefits in COPD. Creatinine, found in meat and fish, did not have additive effects to rehabilitation, while sulforaphane, found in broccoli and wasabi, and curcumin, the pigment in turmeric, may have beneficial antioxidant properties [93 - 95]. Branched chain amino acid supplementation in COPD is associated with positive results including increases in whole body protein synthesis, body weight, fat free mass and arterial blood oxygen levels $[96,97]$. Undernutrition is not a significant problem in asthma, though is a major debilitating feature of COPD. There is promising evidence that nutritional supplementation in COPD is important and can help to alleviate some of the adverse effects of the disease, particularly muscle wasting and weight loss [97].

\section{Conclusion}

Dietary intake appears to be important in both the development and management of respiratory diseases, shown through epidemiological and cross-sectional studies and supported by mechanistic studies in animal models. Although more evidence is needed from intervention studies in humans, there is a clear link for some nutrients and dietary patterns. The dietary patterns associated with benefits in respiratory diseases include high fruit and vegetable intake, Mediterranean style diet, fish and omega-3 intake, while fast food intake and westernized dietary patterns have adverse associations. Though antioxidants are associated with positive effects on inflammation, clinical outcomes and respiratory disease prevention, intervention studies of individual antioxidants do not indicate widespread adoption of supplementation. Greater intake of dietary fibre has been consistently associated with reduced COPD risk, better lung function and reduced respiratory symptoms. Iron deficiency often occurs in COPD, which may be caused by several factors including systemic inflammation, malabsorption of iron from the gut, renal failure (as a consequence of concomitant chronic kidney disease or diabetes mellitus), and medications such as angiotensin-converting enzyme inhibitors and corticosteroids Overall, the evidence indicates that a well-balanced diet with sufficient intake of fresh fruits and vegetables is beneficial to COPD and asthma patients, not only for its potential benefits on the lung, but also for its proven benefits on metabolic and cardiovascular risk.

\section{Compliance with ethical standards}

\section{Acknowledgments}

We would like to thank Dr Anupama Koneru, Principal, Sultan-ul-Uloom College of Pharmacy and all the staff members. Similarly, we would like to express our gratitude to the Management to provide all necessary sources to carry out this review study.

\section{Disclosure of conflict of interest}

All authors declare that they have no conflict of interest.

\section{Statement of ethical approval}

No Animals and were directly used or involved in the study. Moreover it's a review study and no ethical approval is required.

\section{References}

[1] Moorman JE, Akinbami LJ, Bailey CM, et al. National surveillance of asthma: United States, 2001-2010. Vital Health Stat 3. 2012; 35:1-58.

[2] Akinbami LJ, Moorman JE, Bailey C, et al. Trends in asthma prevalence, health care use, and mortality in the United States, 2001-2010. NCHS Data Brief. 2012; 94:1-8.

[3] Akinbami LJ, Moorman JE, Simon AE, et al. Trends in racial disparities for asthma outcomes among children 0 to 17 years, 2001-2010. J Allergy Clin Immunol. 2014; 134:547-553.e5. 
[4] Holsey CN, Collins P, Zahran H. Disparities in asthma care, management, and education among children with asthma Clin Pulm Med. 2013; 20:172-177.

[5] Konttinen H, Sarlio-Lähteenkorva S, Silventoinen K, et al. Socio-economic disparities in the consumption of vegetables, fruit and energy-dense foods: the role of motive priorities. Public Health Nutr. 2013; 16:873-882.

[6] Asher MI, Montefort S, Bjorksten B, Lai CK, Strachan DP, Weiland SK,Williams H, Group IPTS Worldwide time trends in the prevalence of symptoms of asthma, allergic rhinoconjunctivitis, and eczema in childhood: ISAAC Phases One and Three repeat multicountry cross-sectional surveys. Lancet. 2006; 368:733-743.

[7] Guo CH, Liu PJ, Lin KP, Chen PC Nutritional supplement therapy improves oxidative stress, immune response, pulmonary function, and quality of life in allergic asthma patients: An open-label pilot study. Altern. Med. Rev. 2012; 17:42-56.

[8] Haldar P, Pavord ID, Shaw DE, Berry MA, Thomas M, Brightling CE, Wardlaw AJ, Green RH Cluster analysis and clinical asthma phenotypes. Am. J Respir. Crit. Care Med. 2008; 178:218-224.

[9] Umetsu DT Mechanisms by which obesity impacts upon asthma. Thorax. 2017; 72:174-177. doi: 10.1136/thoraxjnl-2016-209130.

[10] Farah CS, Kermode JA, Downie SR, Brown NJ, Hardaker KM, Berend N, King GG, Salome CM Obesity is a determinant of asthma control independent of inflammation and lung mechanics. Chest. 2011; 140:659-666. doi: 10.1378/chest.11-0027

[11] Forno E, Lescher R, Strunk R, Weiss S, Fuhlbrigge A, Celedon JC Childhood Asthma Management Program Research Group Decreased response to inhaled steroids in overweight and obese asthmatic children J Allergy Clin Immunol 2011; 127:741-749 doi: 101016/jjaci201012010

[12] Nurmatov, U Devereux, G Sheikh, A Nutrients and foods for the primary prevention of asthma and allergy: Systematic review and meta-analysis J Allergy Clin Immunol 2011; 127:724-733e30

[13] Varraso, R Fung, TT Barr, RG Hu, FB Willett, W Camargo, CAJ Prospective study of dietary patterns and chronic obstructive pulmonary disease among US women Am J Clin Nutr 2007; 86:488-495

[14] Saadeh, D Salameh, P Baldi, I Raherison, C Diet and allergic diseases among population aged 0 to 18 years: Myth or reality? Nutrients 2013; 5:3399-3423

[15] Willett, WC Sacks, F Trichopoulou, A Drescher, G Ferro-Luzzi, A Helsing, E Trichopoulos, D Mediterranean diet pyramid: A cultural model for healthy eating Am J Clin Nutr 1995; 61:1402S-1406S

[16] Arvaniti, F Priftis, KN Papadimitriou, A Papadopoulos, M Roma, E Kapsokefalou, M Anthracopoulos, MB Panagiotakos, DB Adherence to the Mediterranean type of diet is associated with lower prevalence of asthma symptoms, among 10-12 years old children: The PANACEA study Pediatr Allergy Immunol 2011; 22:283-289

[17] Chatzi, L Kogevinas, M Prenatal and childhood Mediterranean diet and the development of asthma and allergies in children Public Health Nutr 2009; 12:1629-1634

[18] De Batlle, J Garcia-Aymerich, J Barraza-Villarreal, A Antó, JM Romieu, I Mediterranean diet is associated with reduced asthma and rhinitis in Mexican children Allergy 2008; 63:1310-1316

[19] Chatzi, L Torrent, M Romieu, I Garcia-Esteban, R Ferrer, C Vioque, J Kogevinas, M Sunyer, J Mediterranean diet in pregnancy is protective for wheeze and atopy in childhood Thorax 200; 63:507-513

[20] Wood, LG Gibson, PG Dietary factors lead to innate immune activation in asthma Pharmacol Ther 2009; 123:3753

[21] Carey, OJ Cookson, JB Britton, J Tattersfield, AE The effect of lifestyle on wheeze, atopy, and bronchial hyperreactivity in Asian and white children Am J Respir Crit Care Med 1996; 154:537-540

[22] Huang, SL Lin, KC Pan, WH Dietary factors associated with physician-diagnosed asthma and allergic rhinitis in teenagers: Analyses of the first Nutrition and Health Survey in Taiwan Clin Exp Allergy 2001; 31:259-264

[23] Varraso, R Kauffmann, F Leynaert, B Le Moual, N Boutron-Ruault, MC Clavel-Chapelon, F Romieu, I Dietary patterns and asthma in the E3N study Eur Respir J 2009; 33:33-41

[24] Wood, LG Garg, ML Gibson, PG A high-fat challenge increases airway inflammation and impairs bronchodilator recovery in asthma J Allergy Clin Immunol 2011; 127:1133-1140 
[25] Saadeh, D Salameh, P Baldi, I Raherison, C Diet and allergic diseases among population aged 0 to 18 years: Myth or reality? Nutrients 2013; 5: 3399-3423

[26] Grieger, J Wood, L Clifton, V Improving asthma during pregnancy with dietary antioxidants: The current evidence Nutrients 2013; 5:3212-3234

[27] Butland, BK Fehily, AM Elwood, PC Diet, lung function, and lung function decline in a cohort of 2512 middle aged men Thorax 2000; 55:102-108

[28] Carey, IM Strachan, DP Cook, DG Effects of changes in fresh fruit consumption on ventilatory function in healthy British adults Am J Respir Crit Care Med 1998; 158:728-733

[29] Shaheen, SO Jameson, KA Syddall, HE AihieSayer, A Dennison, EM Cooper, C Robinson, SM Hertfordshire Cohort Study Group The relationship of dietary patterns with adult lung function and COPD Eur Respir J 2010; $36: 277-284$

[30] Agler AH, Kurth T, Gaziano JM, et al Randomised vitamin E supplementation and risk of chronic lung disease in the Women's Health Study Thorax 2011; 66:320-325

[31] Thies, F Miles, EA Nebe-von-Caron, G Powell, JR Hurst, TL Newsholme, EA Calder, PC Influence of dietary supplementation with long-chain n-3 or n-6 polyunsaturated fatty acids on blood inflammatory cell populations and functions and on plasma soluble adhesion molecules in healthy adults Lipids 2001; 36:1183-1193

[32] Lo, CJ Chiu, KC Fu, M Chu, A Helton, S Fish oil modulates macrophage P44/P42 mitogenactivated protein kinase activity induced by lipopolysaccharide J Parenter Enter Nutr 2000; 24:159-163

[33] Kelley, DS Taylor, PC Nelson, GJ Schmidt, PC Ferretti, A Erickson, KL Yu, R Chandra, RK Mackey, BE Docosahexaenoic acid ingestion inhibits natural killer cell activity and production of inflammatory mediators in young healthy men Lipids 1999; 34:317-324

[34] Calder, PC n-3 Polyunsaturated fatty acids, inflammation, and inflammatory diseases Am J Clin Nutr 2006; 83: 1505S-1519S

[35] Salam, MT Li, YF Langholz, B Gilliland, FD Maternal fish consumption during pregnancy and risk of early childhood asthma J Asthma 2005; 42:513-518

[36] Klemens, CM Berman, DR Mozurkewich, EL The effect of perinatal omega-3 fatty acid supplementation on inflammatory markers and allergic diseases: A systematic review BJOG 2011; 118:916-925

[37] Shahar, E Boland, LL Folsom, AR Tockman, MS McGovern, PG Eckfeldt, JH Docosahexaenoic acid and smokingrelated chronic obstructive pulmonary disease Am J Respir Crit Care Med 1999; 159:1780-1785

[38] De Batlle, J Sauleda, J Balcells, E Gómez, FP Méndez, M Rodriguez, E Barreiro, E Ferrer, JJ Romieu, I Gea, J et al Association between $\Omega 3$ and $\Omega 6$ fatty acid intakes and serum inflammatory markers in COPD J Nutr Biochem 2012; 23:817-821

[39] Broekhuizen, R Wouters, EF Creutzberg, EC Weling-Scheepers, CA Schols, AM Polyunsaturated fatty acids improve exercise capacity in chronic obstructive pulmonary disease Thorax 2005; 60:376-382

[40] Wood, LG Gibson, PG Garg, ML Biomarkers of lipid peroxidation, airway inflammation and asthma Eur Respir J 2003; 21:177-186

[41] Kelly, FJ Vitamins and respiratory disease: Antioxidant micronutrients in pulmonary health and disease Proc Nutr Soc 2005; 64:510-526

[42] Rahman, I Oxidative stress, chromatin remodeling and gene transcription in inflammation and chronic lung diseases J Biochem Mol Biol 2003; 36:95-109

[43] Ochs-Balcom, HM Grant, BJ Muti, P Sempos, CT Freudenheim, JL Browne, RW McCann, SE Trevisan, M Cassano, PA Iacoviello, $\mathrm{L}$ et al Antioxidants, oxidative stress, and pulmonary function in individuals diagnosed with asthma or COPD Eur J Clin Nutr 2006; 60:991-999

[44] Wood, LG Garg, ML Powell, H Gibson, PG Lycopene-rich treatments modify noneosinophilic airway inflammation in asthma: Proof of concept Free Radic Res 2008; 42:94-102

[45] Clifton, VL Vanderlelie, J Perkins, AV Increased anti-oxidant enzyme activity and biological oxidation in placentae of pregnancies complicated by maternal asthma Placenta 2005; 26:773-779 
[46] Forastiere, F Pistelli, R Sestini, P Fortes, C Renzoni, E Rusconi, F Dell'Orco, V Ciccone, G Bisanti, L The SIDRIA Collaborative Group, I Consumption of fresh fruit rich in vitamin $\mathrm{C}$ and wheezing symptoms in children Thorax 2000; 55:283-288

[47] Shaheen, SO Sterne, JA Thompson, RL Songhurst, CE Margetts, BM Burney, PG Dietary antioxidants and asthma in adults: Population-based case-control study Am J Respir Crit Care Med 2001; 164:1823-1828

[48] Huang, J May, JM Ascorbic acid spares $\alpha$-tocopherol and prevents lipid peroxidation in cultured H4IIE liver cells Mol Cell Biochem 2003; 247:171-176

[49] Hernandez, ML Wagner, JG Kala, A Mills, K Wells, HB Alexis, NE Lay, JC Jiang, Q Zhang, H Zhou, H et al Vitamin E, $\gamma$-tocopherol, reduces airway neutrophil recruitment after inhaled endotoxin challenge in rats and in healthy volunteers Free Radic Biol Med 2013; 60:56-62

[50] Tug, T Karatas, F Terzi, SM Antioxidant vitamins (A, C and E) and malondialdehyde levels in acute exacerbation and stable periods of patients with chronic obstructive pulmonary disease Clin Investig Med 2004; 27:123-128

[51] Daga, MK Chhabra, R Sharma, B Mishra, TK Effects of exogenous vitamin E supplementation on the levels of oxidants and antioxidants in chronic obstructive pulmonary disease J Biosci 2003; 28:7-11

[52] Agler, AH Kurth, T Gaziano, JM Buring, JE Cassano, PA Randomised vitamin E supplementation and risk of chronic lung disease in the Women's Health Study Thorax 2011; 66:320-325

[53] Holick, MF Vitamin D deficiency N Engl J Med 2007; 357:266-281

[54] Hart, PH Lucas, RM Walsh, JP Zosky, GR Whitehouse, AJO Zhu, K Allen, KL Kusel, MM Anderson, D Mountain, JA Vitamin D in Fetal Development: Findings From a Birth Cohort Study Pediatrics 2014, doi:101542/peds20141860

[55] Hart, PH Gorman, S Finlay-Jones, JJ Modulation of the immune system by UV radiation: More than just the effects of vitamin D? Nat Rev Immunol 2011; 11:584-596

[56] Foong, R Zosky, G Vitamin D deficiency and the lung: Disease initiator or disease modifier? Nutrients 2013; 5:2880-2900

[57] Hiemstra, PS The role of epithelial $\beta$-defensins and cathelicidins in host defense of the lung Exp Lung Res 2007; 33:537-542

[58] Brehm, JM Schuemann, B Fuhlbrigge, AL Hollis, BW Strunk, RC Zeiger, RS Weiss, ST Litonjua, AA Serum vitamin D levels and severe asthma exacerbations in the Childhood Asthma Management Program study J Allergy Clin Immonol 2010; 126:52-58

[59] Zosky, GR Hart, PH Whitehouse, AJ Kusel, MM Ang, W Foong, RE Chen, L Holt, PG Sly, PD Hall, GL Vitamin D deficiency at 16 to 20 weeks' gestation is associated with impaired lung function and asthma at 6 years of age Ann Am Thorac Soc 2014; 11:571-577

[60] Black, PN Scragg, R Relationship between serum 25-hydroxyvitamin D and pulmonary function survey Chest $2005 ; 128: 3792-3798$

[61] Persson, LJ Aanerud, M Hiemstra, PS Hardie, JA Bakke, PS Eagan, TM Chronic obstructive pulmonary disease is associated with low levels of vitamin D PLoS One 2012; 7:e38934

[62] Lehouck, A Mathieu, C Carremans, C Baeke, F Verhaegen, J Van Eldere, J Decallonne, B Bouillon, R Decramer, $\mathrm{M}$ Janssens, W High doses of vitamin $\mathrm{D}$ to reduce exacerbations in chronic obstructive pulmonary disease: A randomized trial Ann Intern Med 2012; 156: 105-114

[63] Janssens W, Lehouck A, Carremans C, et al Vitamin D beyond bones in chronic obstructive pulmonary disease: time to act Am J RespirCrit Care Med 2009; 179:630-636

[64] Black PN, Scragg R Relationship between serum 25-hydroxyvitamin D and pulmonary function in the third national health and nutrition examination survey Chest 2005; 128:3792-3798

[65] Ginde AA, Mansbach JM, Camargo CA Jr Association between serum 25-hydroxyvitamin D level and upper respiratory tract infection in the Third National Health and Nutrition Examination Survey Arch Intern Med 2009; 169:384-390

[66] Kunisaki KM, Niewoehner DE, Singh RJ, et al Vitamin D status and longitudinal lung function decline in the Lung Health Study EurRespir J 2011; 37:238-243 
[67] Lange NE, Sparrow D, Vokonas P, et al Vitamin D deficiency, smoking, and lung function in the Normative Aging Study Am J RespirCrit Care Med 2012; 186:616-621

[68] Afzal S, Lange P, Bojesen SE, et al Plasma 25-hydroxyvitamin D, lung function and risk of chronic obstructive pulmonary disease Thorax 2014; 69:24-31

[69] Lehouck A, Mathieu C, Carremans C, et al High doses of vitamin D to reduce exacerbations in chronic obstructive pulmonary disease: a randomized trial Ann Intern Med 2012; 156:105-114

[70] Matthew, R Altura, B The role of magnesium in lung diseases: Asthma, allergy, and pulmonary hypertension Magnes Trace Elem 1991; 10:220-228

[71] Baker, J Tunnicliffe, W Duncanson, R Ayres, J Dietary antioxidants in type 1 brittle asthma: A case control study Thorax 1999; 54:115-118

[72] Gilliand, F Berhane, K Li, Y Kim, D Margolis, H Dietary magnesium, potassium, sodium and childrens lung function Am J Epidemiol 2002; 155:125-131

[73] Kim, J-H Ellwood, P Asher, MI Diet and asthma: Looking back, moving forward Respir Res 2009; 10:49-55

[74] Kadrabova, J Mad'aric, A Kovacikova, Z Podivínsky, F Ginter, E Gazdík, F Selenium status is decreased in patients with intrinsic asthma Biol Trace Elem Res 1996; 52:241-248

[75] Devereux, G McNeill, G Newman, G Turner, S Craig, L Martindale, S Helms, P Seaton, A Early childhood wheezing symptoms in relation to plasma selenium in pregnant mothers and neonates Clin Exp Allergy 2007; 37:1000-1008

[76] Shaheen, SO Newson, RB Rayman, MP Wong, AP Tumilty, MK Phillips, JM Potts, JF Kelly, FJ White, PT Burney, PG Randomised, double blind, placebo controlled trial of selenium supplementation in adult asthma Thorax 2007; 62:483-490

[77] Tanaka, T Takahashi, R Flavonoids and asthma Nutrients 2013; 5:2128-2143

[78] Manach, C Scalbert, A Morand, C Remesy, C Jimenez, L Polyphenols: Food sources and bioavailability Am J Clin Nutr 2004; 79:727-747

[79] Hirano, T Higa, S Arimitsu, J Naka, T Shima, Y Ohshima, S Fujimoto, M Yamadori, T Kawase, I Tanaka, T Flavonoids such as luteolin, fisetin and apigenin are inhibitors of interleukin-4 and interleukin-13 production by activated human basophils Int Arch Allergy Immunol 2004; 134:135-140

[80] Belcaro, G Luzzi, R Cesinaro di Rocco, P Cesarone, MR Dugall, M Feragalli, B Errichi, BM Ippolito, E Grossi, MG Hosoi, $M$ et al Pycnogenol improvements in asthma management Panminerva Med 2011; 53:57-64

[81] Medzhitov, R Origin and physiological roles of inflammation Nature 2008; 454:428-435

[82] Berthon, BS Macdonald-Wicks, LK Gibson, PG Wood, LG Investigation of the association between dietary intake, disease severity and airway inflammation in asthma Respirology 2013; 18:447-454

[83] Procaccini, C Jirillo, E Matarese, G Leptin as an immunomodulator Mol Aspects Med 2012; 33:35-45

[84] Shore, SA Terry, RD Flynt, L Xu, A Hug, C Adiponectin attenuates allergen-induced airway inflammation and hyperresponsiveness in mice J Allergy Clin Immonol 2006; 118:389-395

[85] Franssen, FM O’Donnell, DE Goossens, GH Blaak, EE Schols, AM Obesity and the lung: 5 Obesity and COPD Thorax 2008; 63:1110-1117

[86] Furukawa, T Hasegawa, T Suzuki, K Koya, T Sakagami, T Youkou, A Kagamu, H Arakawa, M Gejyo, F Narita, I et al Influence of underweight on asthma control Allergol Int 2012; 61:489-496

[87] Itoh, M Tsuji, T Nemoto, K Nakamura, H Aoshiba, K Undernutrition in patients with COPD and its treatment Nutrients 2013; 5:1316-1335

[88] Hallin, R Koivisto-Hursti, UK Lindberg, E Janson, C Nutritional status, dietary energy intake and the risk of exacerbations in patients with chronic obstructive pulmonary disease (COPD) Respir Med 2006; 100:561-567

[89] Grönberg, AM Slinde, F Engström, CP Hulthén, L Larsson, S Dietary problems in patients with severe chronic obstructive disease J Hum Nutr Diet 2005; 18:445-452

[90] Wilson, DO Donahoe, M Rogers, RM Pennock, BE Metabolic rate and weight loss in chronic obstructive lung disease J Parenter Enter Nutr 1990; 14:7-11 
[91] Gan, WQ Man, SF Senthilselvan, A Sin, DD Association between chronic obstructive pulmonary disease and systemic inflammation: A systematic review and a meta-analysis Thorax 2004; 59:574-580

[92] Ferreira, IM Brooks, D White, J Goldstein, R Nutritional supplementation for stable chronic obstructive pulmonary disease Cochrane Database Syst Rev 2012; 12:CD000998

[93] Al-Ghimlas, F Todd, DC Creatine supplementation for patients with COPD receiving pulmonary rehabilitation: A systematic review and meta-analysis Respirology 2010; 15:785-795

[94] Morimitsu, Y Nakagawa, Y Hayashi, K Fujii, H Kumagai, T Nakamura, Y Osawa, T Horio, F Itoh, K Iida, K et al A sulforaphane analogue that potently activates the Nrf2- dependent detoxification pathway J Biol Chem 2002; 277:3456-3463

[95] Meja, KK Rajendrasozhan, S Adenuga, D Biswas, SK Sundar, IK Spooner, G Marwick, JA Chakravarty, P Fletcher, D Whittaker, $\mathrm{P}$ et al Curcumin restores corticosteroid function in monocytes exposed to oxidants by maintaining HDAC2 Am J Respir Cell Mol Biol 2008; 39:312-323

[96] Engelen, MP Rutten, EP de Castro, CL Wouters, EF Schols, AM Deutz, NE.

[97] Dal Negro, RW Aquilani, R Bertacco, S Boschi, FMC Tognella, S Comprehensive effects of supplemented essential amino acids in patients with severe COPD and sarcopenia Monaldi Arch Chest Dis 2010; 73:25-33 